\title{
Photosensitive-polyimide based method for fabricating various neural electrode architectures
}

\author{
Yasuhiro X. Kato ${ }^{1 *}$, Shigeto Furukawa ${ }^{2}$, Kazuyuki Samejima ${ }^{1}$, Naoyuki Hironaka $^{2}$ and \\ Makio Kashino ${ }^{2}$ \\ Brain Science Institute, Tamagawa University, Machida, Tokyo, Japan \\ 2 Perception and Emotion Research Group, Human and Information Science Laboratory, NTT Communication Science Laboratories, Nippon Telegraph and \\ Telephone Corporation, Atsugi, Kanagawa, Japan
}

\section{Edited by:}

Martin Stelzle, University of

Tübingen, Germany

Reviewed by:

Martin Stelzle, University of

Tübingen, Germany

Hun-Kuk Park, Kyung Hee

University, South Korea

\section{*Correspondence:}

Yasuhiro X. Kato, Brain Science

Institute, Tamagawa University,

6-1-1, Tamagawa gakuen, Machida,

Tokyo 194-8610, Japan.

e-mail:xige-kato@umin.ac.jp
An extensive photosensitive-polyimide (PSPI)-based method for designing and fabricating various neural electrode architectures was developed. The method aims to broaden the design flexibility and expand the fabrication capability for neural electrodes to improve the quality of recorded signals and integrate other functions. After characterizing PSPI's properties for micromachining processes, we successfully designed and fabricated various neural electrodes even on a non-flat substrate using only one PSPI as an insulation material and without the time-consuming dry etching processes. The fabricated neural electrodes were an electrocorticogram (ECoG) electrode, a mesh intracortical electrode with a unique lattice-like mesh structure to fixate neural tissue, and a guide cannula electrode with recording microelectrodes placed on the curved surface of a guide cannula as a microdialysis probe. In vivo neural recordings using anesthetized rats demonstrated that these electrodes can be used to record neural activities repeatedly without any breakage and mechanical failures, which potentially promises stable recordings for long periods of time. These successes make us believe that this PSPI-based fabrication is a powerful method, permitting flexible design, and easy optimization of electrode architectures for a variety of electrophysiological experimental research with improved neural recording performance.

Keywords: photosensitive material, neural electrode, ECoG, mesh-structure, guide cannula electrode, MEMS

\section{INTRODUCTION}

Micro-electro-mechanical systems (MEMS) surface-micromachining technologies have been used to fabricate neural electrodes for interfacing with the nervous system, and these neural electrodes have been widely accepted for use in electrophysiological investigations (Najafi et al., 1990; Campbell et al., 1991; Wise and Najafi, 1991; Metz et al., 2001; Rousche et al., 2001; Stieglitz and Gross, 2002; Takahashi et al., 2003; Takeuchi et al., 2005; Hollenberg et al., 2006; Cheung et al., 2007; Mercanzini et al., 2008; Chen et al., 2009; Myllymaa et al., 2009; Jackson et al., 2010; Rothschild, 2010; Muthuswamy et al., 2011). Existing MEMS-based neural electrodes, however, cannot satisfy the increasing demand for improved quality of recorded signals and for the integration of other functions.

For example, a flexible neural electrode was recently proposed to minimize mechanical mismatch between the electrode and tissue after the electrode's implantation for a stable long-term recording, but it lacks a mechanical function to fixate tissue. Thus, there is a need for new designs that offer flexibility with a tissue fixation structure. Another example is the demand for the capability to record electrical and chemical neural activities simultaneously by integrating a neural electrode with a microdialysis probe (Ludvig et al., 1994; Obrenovitch et al., 1994; Gruss et al., 1999). This requires precise patterning of recording electrodes on the non-flat surface of the guide cannula of a microdialysis probe. Other issues of interest are designs and fabrication processes that allow easy and rapid optimization depending on experimental requirements (i.e., alignment, diameter, and pitch of recording microelectrodes) (Hanna and Johnson, 1968; Takahashi et al., 2005).

Meeting these demands requires further advances in MEMSbased fabrication methods. Here we propose a method based on photosensitive-polyimide (PSPI). PSPI is a photosensitive material that can be precisely patterned by photolithography on flat surfaces. In this study, we first examined the material properties of PSPI. On the basis of the results, we demonstrated the advantages of the PSPI-based fabrication method by fabricating three different types of neural electrodes: an electrocorticogram (ECoG) electrode (or epidural surface electrode), a mesh intracortical electrode, and a guide cannula electrode of a microdialysis probe. A standard neural ECoG electrode was developed to evaluate the efficacy of the fabrication process. The mesh intracortical electrode was designed to have a mesh structure in an insertion site as an anchor for fixating tissue in order to alleviate mechanical mismatch and follow the movement of brain micromotion. To examine whether our method can be used to pattern recording electrodes on non-flat surfaces, we applied it to the curved surface of a guide cannula of a microdialysis probe for simultaneous recording of electrical and chemical neural activities. The fabricated neural electrodes were evaluated by in vivo electrophysiological experiments using anesthetized rats. 


\section{METHODS \\ CHOICE OF MATERIALS}

Compared with conventional flexible materials, such as non-PSPI and poly (chloro-para-xylylene) (Parylene-C), PSPI provides similar good dielectrics with excellent thermal stability and high flexibility, good mechanical and electrical properties, and high chemical resistance as shown in Table 1. The important advantage of PSPI over more conventional polymers is that PSPI is a lightcurable polymer, or in other words, a photosensitive material. This permits optimal light-curing conditions, which means only one photosensitive material is required for fabrication (details are described in Shrinkage Effect Of Curing Process of Results). An in vitro study (Sun et al., 2009) suggested that PSPI is not cytotoxic and does not induce adverse biological effects, which offers excellent long-term stability. As mentioned above, unlike other conventional flexible materials, PSPI does not need to be dry etched (Figure 1) for neural electrode fabrication. The elimination of the dry etching process simplifies the time-consuming processes requiring multilevel schemes (Figures 1A-5-A-9) and reduces equipment and maintenance cost. Photolithographic patterning is also advantageous in that the patterning substrate is not limited to one with a flat surface. Thus, PSPI allows flexible design architectures and fabrication of multichannel neural electrodes with more options for optimization of the configuration and size depending on the experimental purposes, with improvement of process yields.

A number of commercial PSPIs are available today, such as the Fujifilm Durimide series, Toray Industries PW-1000 series, and HD microsystem PD series. Among them, we chose Fujifilm Durimide 7510 (Fujifilm Electronic Materials Co., Ltd., Tokyo, Japan) because the theoretical coating thickness ranges from 3 to $15 \mu \mathrm{m}$, which is adequate for neural electrodes, and because its good biocompatibility has already been shown in an in vitro study (Sun et al., 2009). Further, its physical properties, such as Young's modulus and volume resistivity, are almost equivalent to those of other conventional flexible materials (see Table $\mathbf{1}$ ).

Metals, such as $\mathrm{Au}, \mathrm{Ir}, \mathrm{Pt}$, and $\mathrm{W}$, are widely used in neural electrodes for the individual recording microelectrode sites, interconnect lines, and connection pads. For this study, we selected $\mathrm{Au}$ because of its low resistance, flexibility, and biocompatibility (Loeb et al., 1977; Charlson et al., 1992; Takeuchi et al., 2004). With a Young's modulus of $78 \mathrm{GPa}$, Au has enough flexibility for neural electrodes compared to $\mathrm{Ir}, \mathrm{Pt}$, and $\mathrm{W}$, whose respective
Young's moduli are 529, 152, and $345 \mathrm{GPa}$. With this flexibility, the electrode will give enough to follow brain movement without fracturing. Further, due the low adhesiveness between $\mathrm{Au}$ and polyimide, a thin chromium film was also coated on the first polyimide layer to improve the Au's adhesiveness.

\section{SHRINKAGE EFFECT OF CURING PROCESS}

PSPI was imidized by thermal curing to increase resistance to solvents and basic solutions. The imidization leads to shrinkage of PSPI in-plane and orthogonal to the substrate. The amount of this shrinkage should be taken into consideration when fabricating an electrode in order for final products to have desired dimensions. Thus, we examined the anisotropic shrinkage effect of the thermal curing in soft-baked and hard-baked PSPI. To determine the thickness of the base substrate, we formed a U-shaped lineand-space $(\mathrm{L} / \mathrm{S})$ pattern at $1000 \mathrm{rpm}$ of spin-coating speed for $\mathrm{L} / \mathrm{S}=50 / 50 \mu \mathrm{m}$ and $2000 \mathrm{rpm}$ for $\mathrm{L} / \mathrm{S}=25 / 25 \mu \mathrm{m}$. We tested $4000 \mathrm{rpm}$ of spin-coating speed for patterning PSPI into a $20 \mu \mathrm{m}$ gap shape and tested a $10 \mu \mathrm{m}$-circular shape to define the thickness of the recording microelectrode's sites. PSPI was spin-coated on a glass substrate and soft-baked in an oven at $60^{\circ} \mathrm{C}$ for $2 \mathrm{~min}$ and at $100^{\circ} \mathrm{C}$ for $5 \mathrm{~min}$ to remove solvent. It was exposed through a photomask and etched using solvent developers into each shape. The coating was then post-baked to remove residual solvent and improve solvent resistance. The temperature was gradually raised in $50^{\circ} \mathrm{C}$ increments to $350^{\circ} \mathrm{C}$ every $10 \mathrm{~min}$ and then maintained at $350^{\circ} \mathrm{C}$ for $1 \mathrm{~h}$. The profile of the cured PSPI was measured with a laser microscope (VK-8500, Keyence, Osaka, Japan) and a profilometer (Alpha-Step, Tencor Instruments, Mountain View, CA, USA). The coating thickness was also measured for spin-coating speeds from 1000 to $5000 \mathrm{rpm}$.

\section{DESIGNS OF NEURAL ELECTRODES}

To demonstrate the feasibility of PSPI-based fabrication for neural electrodes, we built three different types of neural electrodes. The spin-coating speeds and size limitations were determined from the results of an analysis of the shrinkage effect of the curing process (See Shrinkage Effect Of Curing Process in Results and Discussion). First, we designed an ECoG electrode for the less invasive multichannel recordings of ECoGs. The ECoG electrode is placed epidurally on the neocortex, particularly, rat auditory cortex. In our design, the through-holes for soldering pins of the

Table 1 | Physical properties of flexible materials and silicon.

\begin{tabular}{|c|c|c|c|c|}
\hline Physical properties & $\begin{array}{l}\text { Photosensitive material } \\
\text { Photosensitive-polyimide } \\
\text { (Fujifilm, Durimide 7510) }\end{array}$ & \multicolumn{3}{|c|}{ Non-photosensitive material } \\
\hline Tensile strength [MPa] & 215 & 350 & 68.9 & 12013 \\
\hline Young's modulus [GPa] & 2.5 & 8.54 & $2-5$ & $130-190$ \\
\hline Glass transition $\left[{ }^{\circ} \mathrm{C}\right]$ & 285 & $>400$ & $87-89$ & none \\
\hline Water absorption [\%] & 0.06 & $>0.4$ & 1.08 & none \\
\hline
\end{tabular}




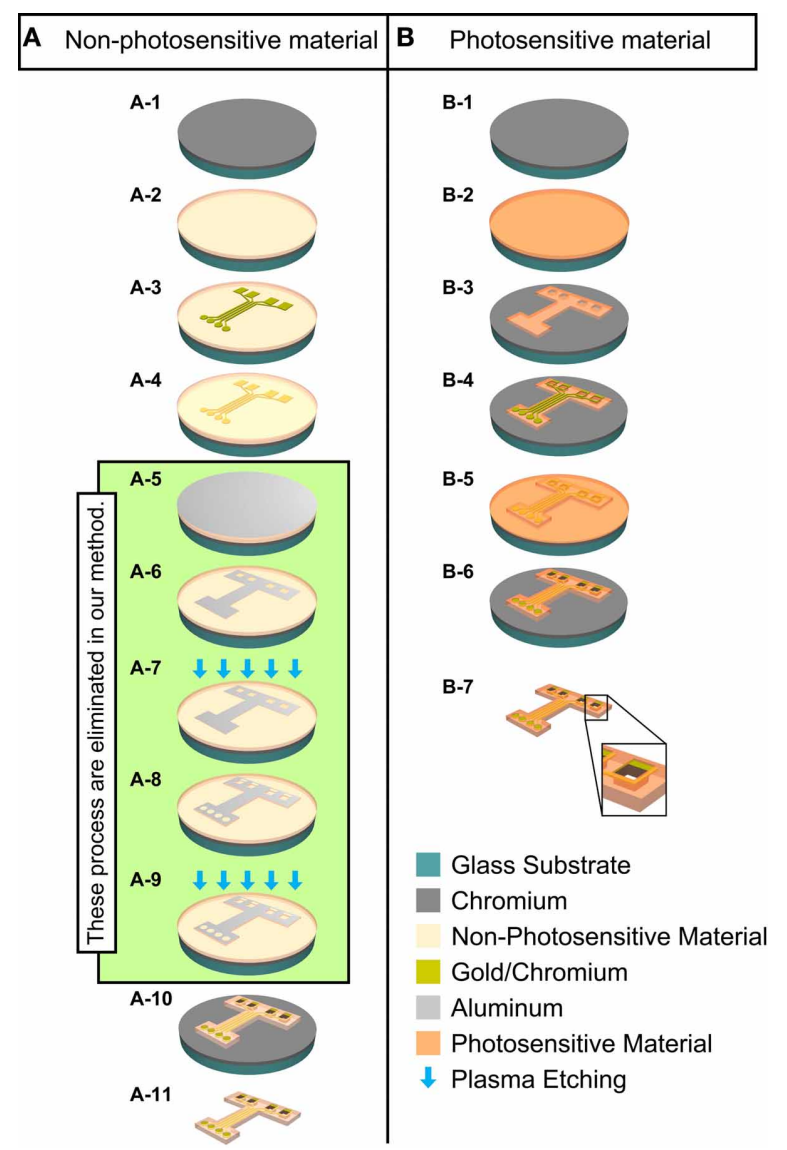

FIGURE 1 | Schematic diagram of the manufacturing process for the ECoG electrode with MEMS surface-micromachining technologies.

Column (A): Conventional fabrication method for non-photosensitive material (non-PSM). Column (B): Fabrication method in this study for photosensitive material (PSM). Dry etching process is green color area from (A-5) to (A-9). (A-1) $\mathrm{Cr}$ is deposited on glass on substrate. (A-2) Non-PSM is deposited. (A-3) Chromium/gold is deposited and the recording microelectrodes and hard wiring are patterned. (A-4) Non-PSM is deposited again. (A-5) Aluminum is deposited as a mask for plasma etching. (A-6) Aluminum mask is patterned for the outer geometry and the through-holes of the ECoG electrode. (A-7) Non-PSM is patterned to define the outer geometry and the through-holes of the ECoG electrode by plasma etching. (A-8) Aluminum mask is patterned for the outer geometry, the exposed recording microelectrode sites, and the through-holes by plasma etching. (A-9) Non-PSM is patterned to expose the outer geometry, the exposed recording microelectrode sites, and the through-holes by plasma etching. (A-10) Aluminum is removed. (A-11) The ECoG electrode is lifted off. (B-1) $\mathrm{Cr}$ is deposited on glass on substrate. (B-2) PSM is deposited on substrate. (B-3) PSM is patterned to define the outer geometry and the through-holes of the ECoG electrode. (B-4) Chromium/gold is deposited and the recording microelectrodes and hard wiring are patterned. (B-5) PSM is deposited again. (B-6) The outer geometry, the exposed recording microelectrode sites, and the through-holes of the ECoG electrode are patterned. (B-7) The ECoG electrode is lifted off. Large box at the bottom is a magnified illustration of a through-hole.

connector are located on the connector side so that the recording side and connector side can be placed on opposite faces without unwanted deformation. Further, the flexibility of the PSPI-based ECoG electrode allows it to fit the curved cortical surface and follow brain movement, such as a cardiac and respiratory pulsation. For the ECoG electrode, the diameter of the recording microelectrodes was $100 \mu \mathrm{m}$, and the pitches of the recording microelectrode sites were $500 \mu \mathrm{m}$ on the dorso-ventral axis and $700 \mu \mathrm{m}$ on the rostral-caudal axis. The placement area of recording microelectrode site was $2.9 \times 1.2 \mathrm{~mm}$ (excluding the most ventro-rostral part of the electrode), and the overall placement area was $4.6 \times 2.0 \mathrm{~mm}$. The area of the overall auditory cortex in rat is approximately $4 \times 3 \mathrm{~mm}$ (Sally and Kell, 1988; Kilgard and Merzenich, 1999; Polley et al., 2007; Ohl et al., 2000), and the designed ECoG electrode would cover the anterior and primary auditory cortex. The diameter of $100 \mu \mathrm{m}$ and pitch of $700 \mu \mathrm{m}$ were chosen because they are appropriate dimensions for observing the spatially distributed response of the characteristic frequency (Ohl et al., 2000; Polley et al., 2007). The configuration of the through-holes was designed for the cross-sectional area of $0.30 \times 0.11 \mathrm{~mm}$ so that there would be enough space for the pin of the connector (Nanoconnector, Omnetics Connector Corp, Minneapolis, MN, USA; cross-sectional area of $0.20 \times 0.06 \mathrm{~mm}$ ) to pass through and thereby be easy to solder.

Second, we designed a mesh structure in a mesh intracortical electrode by eliminating an excess parts of the insulation layers that were not mechanically and electronically required for signal recording. Neural tissue fills the spaces in lattice-like mesh of the wire and the insulated part as it returns after having been pressed downward by the electrode's insertion. In this way, the neural tissue becomes fixated. Considering the effect of shrinkage and expansion of the top and bottom faces of PSPI, we assumed that a PSPI-based fabrication method would allow precise patterning for the fabrication of a complicated and fine mesh structure. From the results of the examination of the shrinkage effect of the curing process (See Shrinkage Effect Of Curing Process in Results and Discussion), we found that the insulation layers sandwiched more than a $25 \%$ larger margin of the width in the metalized interconnection line, which would prevent unwanted exposure of the metalized area and thereby ensure excellent electrical insulation. We made the area of the recording microelectrode in the metallization layer larger than the aperture area in the top insulation layer by more than $20 \%$. This was done to prevent delamination of the recording microelectrode. Thus, for the dimensions of the mesh intracortical electrode, we chose a respective diameter and pitch of recording microelectrode sites of 40 and $80 \mu \mathrm{m}$, a reference electrode size of $30 \times 180 \mu \mathrm{m}$, interconnection line width of $15 \mu \mathrm{m}$, an insulated mesh width in the mesh structure area of $30 \mu \mathrm{m}$, the minimum space between insulated mesh area of $20 \mu \mathrm{m}$, and the implantation length of $2645 \mu \mathrm{m}$.

Third, we used PSPI patterning to design and fabricate electrodes on a curved surface, particularly on the guide cannula of a microdialysis probe for simultaneous recording of electrical and chemical neural activities. Earlier methods inserted a recording electrode into a guide cannula (Obrenovitch et al., 1994) or attached a recording electrode to a guide cannula, which were independently fabricated (Ludvig et al., 1994; Gruss et al., 1999). Our method, in which an electrode is fabricated directly on the surface of a guide cannula, is advantageous over these earlier methods. This is because we can place a number of electrode sites at desired locations on the cannula without increasing the total 
volume. Further, our method preserves an advantage of conventional guide-cannula-based methods in that it allows us to replace the microdialysis probe in case of failure while keeping the guide cannula and the recording sites in place. In order to achieve precise control of the etching conditions to expose the recording microelectrodes and the patterning of the hard wiring on the curved surface of the guide cannula, we applied only a wet process for this fabrication with PSPI and electrodeposition resist. PSPI was used for the base and insulating layers. Chromiumgold patterned with electrodeposition resist as a sacrificial layer was used for individual recording microelectrode sites, interconnect lines, and connection pads. The guide cannula electrode was designed to record a local field potential from rat auditory cortex. Its dimensions were as follows: interconnection line width of $50 \mu \mathrm{m}$, minimum space between interconnection lines of $50 \mu \mathrm{m}$, largest interconnection line length of $1915 \mu \mathrm{m}$, diameter of recording microelectrode sites of $100 \mu \mathrm{m}$, distances of recording microelectrode sites from the tip of 100, 300, and $1800 \mu \mathrm{m}$, and implantation length of $10 \mathrm{~mm}$. The recording microelectrode at the farthest side from the tip was also used as a reference electrode.

\section{FABRICATION OF NEURAL ELECTRODES}

We used only a wet chemical patterning process to fabricate PSPIbased neural electrodes with a MEMS surface-micromachining technique. Similar structures and processes have been previously reported (Najafi et al., 1990; Wise and Najafi, 1991; González and Rodríguez, 1997; Stieglitz et al., 2000; Rousche et al., 2001; Takeuchi et al., 2005). The fabrication process is depicted in Figure 1. The same method was used for the fabrication of the ECoG and mesh intracortical electrodes. A first thick layer of PSPI was spin-coated at $1600 \mathrm{rpm}$ on a Cr-coated glass substrate to a thickness of about $15 \mu \mathrm{m}$. A Cr layer was used to lift-off the fabricated electrode in the final step without any breakage. The PSPI coating was soft-baked at $60^{\circ} \mathrm{C}$ for $2 \mathrm{~min}$ and $100^{\circ} \mathrm{C}$ for $5 \mathrm{~min}$. It was exposed through a photomask and etched using solvent developers into an outline of the neural electrodes. The coating was then post-baked, where its temperature was gradually raised in $50^{\circ} \mathrm{C}$ increments to $350^{\circ} \mathrm{C}$ every $10 \mathrm{~min}$ and then maintained at $350^{\circ} \mathrm{C}$ for $1 \mathrm{~h}$. Next, a metallization layer composed of $500 \AA$ of chromium and $3000 \AA$ of gold was deposited by vacuum evaporation and structured by using the lift-off technique for individual recording microelectrode sites, interconnect lines, and connection pads. Then, a second PSPI layer with a thickness of about $3 \mu \mathrm{m}$ was spin-coated at $5000 \mathrm{rpm}$. The PSPI coating was soft-baked at $60^{\circ} \mathrm{C}$ for $2 \mathrm{~min}$ and $100^{\circ} \mathrm{C}$ for $3 \mathrm{~min}$. The second coating was wet-etched to define the electrode sites and the outer geometry of the neural electrodes and then fully cured to insulate the metallization layer. It was exposed through a photomask and etched with solvent developers into an outline of the neural electrodes. The coating was post-baked by using the same method as for the first PSPI layer. Then, a protective resist (OFPR800, Tokyo Ohka Kogyo Co., Ltd., Kanagawa, Japan) was coated to prevent damage to the through-holes of the ECoG and to the mesh structure of the mesh intracortical electrode during the release process. Both electrodes were then released by wet etching (Ferric Chloride, Tsurumi Soda Co., Ltd.,
Kanagawa, Japan) the Cr layer on glass substrates. After removal of the protective resist by immersion in acetone, the final process, assembly of the fabricated neural electrodes with a connector, was performed. A plastic plate was manually cut with a blade and bonded to the connector side of the electrodes with an epoxidebased adhesive (Araldite, Huntsman Advanced Materials, Basel, Switzerland). This was done to reinforce the base of the connector side of the neural electrode for the repeated connection and removal of a buffer amplifier. A connector (Nanoconnector, Omnetics Connector Corp) was then soldered to the gold connector pads of the electrodes. Further, an epoxide-based adhesive was applied to the connector region as insulation and a shield from contact with tissue.

Figure 2 illustrates the fabrication process for the guide cannula electrode of the microdialysis probe. This process was similar to that of the ECoG and the mesh intracortical electrodes. First, the microdialysis probe was taken apart and the stainless-steel

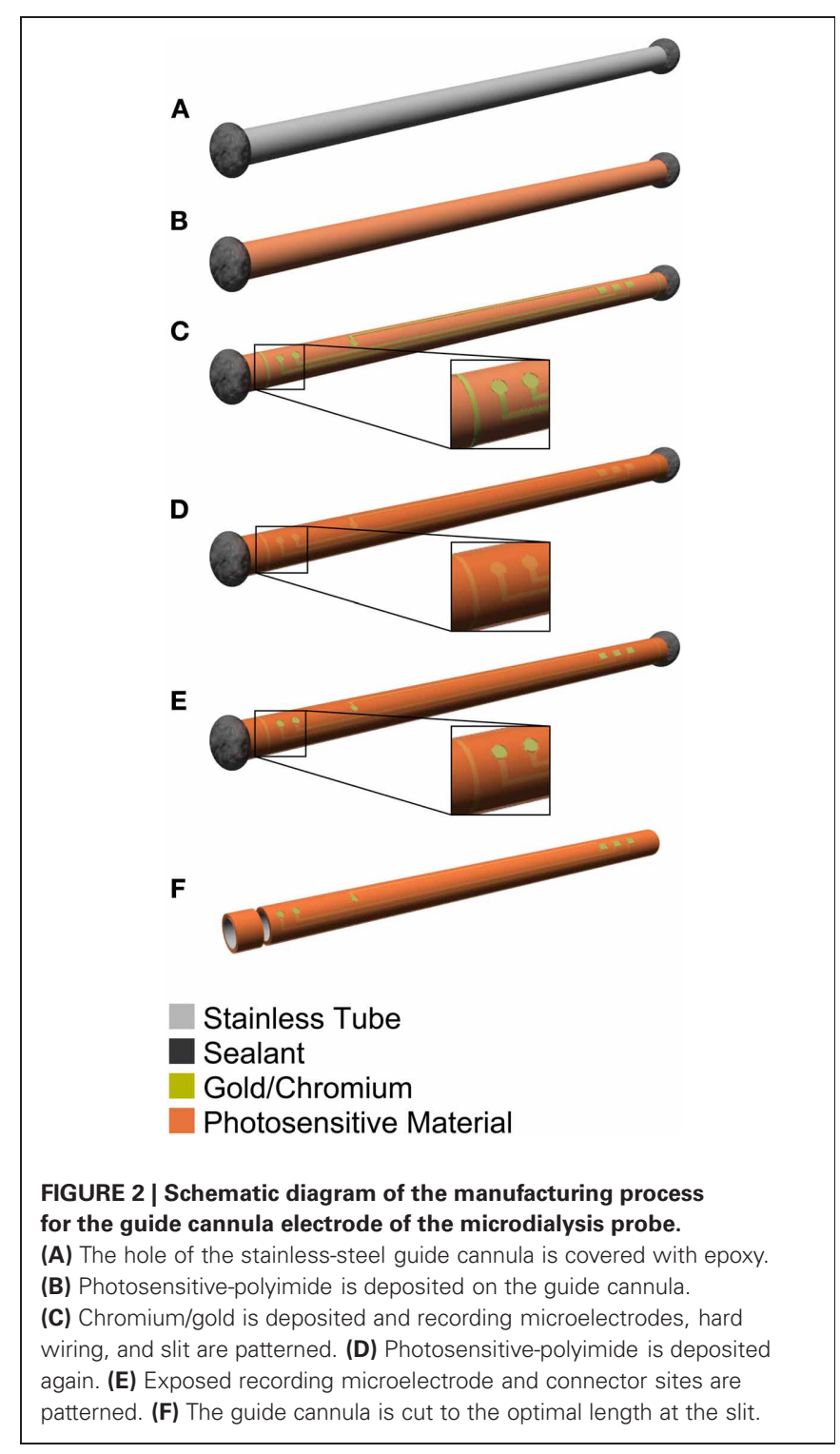


guide cannula $(0.4 \mathrm{~mm}$ ID, $0.5 \mathrm{~mm}$ OD) was removed. The hole of the guide cannula was covered with epoxy (High Super 5, Cemedine Co., Ltd., Tokyo, Japan). This was done to keep impurities out of the guide cannula and prevent the microdialysis membrane from breaking when it is inserted in the guide cannula. Next, in order to insulate the stainless-steel guide cannula, PSPI was spin-coated at $2500 \mathrm{rpm}$ on the curved surface of the guide cannula in an upright position. The PSPI coating was softbaked at $60^{\circ} \mathrm{C}$ for $2 \mathrm{~min}$ and $100^{\circ} \mathrm{C}$ for $15 \mathrm{~min}$ with the upright position maintained. This process was done for one side of the guide cannula first and then repeated for the other side. The coating was then post-baked by using the same condition as in the process for the ECoG and the mesh intracortical electrodes. A metallization layer of chromium and gold was deposited by vacuum evaporation and structured by using the lift-off technique for individual recording microelectrode sites, interconnect lines, connection pads, and slits near both ends as cutoff marks. An electrodeposited coating (Elecoat EU-XC, Shimizu Co., Ltd., Osaka, Japan) was used as a sacrificial layer. A second PSPI layer with a thickness of about $2 \mu \mathrm{m}$ was coated and cured by using the same method as for the first PSPI layer. The second PSPI coating was wet-etched to define the recording microelectrode sites and then fully cured to insulate the metallization layer. We used a dicer to cut the guide cannula to the optimal length at the slits (DAD-2H/6T, Disco Corporation, Tokyo, Japan), and soldered the connector to it. Finally, the connector region was covered with black rubber adhesive (Y-902, SOMAY-Q TECHNOLOGY Corporation, Ibaraki, Japan) and the screw cap and microdialysis membrane were assembled.

\section{ELECTRICAL CHARACTERISTICS}

The impedances of the recording electrodes were measured to characterize the recording sites. The measurement was performed with an LCR meter (LCR HiTESTER 3522-50, Hioki E. E. Corporation, Nagano, Japan) at $100 \mathrm{~Hz}, 1 \mathrm{kHz}, 10 \mathrm{kHz}$, and $100 \mathrm{kHz}$. The recording sites were fully immersed in a $0.9 \%$ saline solution (Otsuka Pharmaceutical Co., Ltd., Tokyo, Japan) and then measured at room temperature.

\section{In vivo NEURAL RECORDINS}

All animal experiments were performed in accordance with the "Guide for Care and Use of Laboratory Animals" (Institute for Laboratory Animal Research, National Research Council) and were approved by the Animal Experimental Committee of NTT Communication Science Laboratories. After the animals (male Wistar rats with weight of 300-400 g, and 3-6 months old) had been given an intra-muscular injection of atropine sulfate $(0.2 \mathrm{mg} / \mathrm{kg})$, they were anesthetized with an intra-muscular injection of a 2:1 mixture of ketamine hydrochloride $(50 \mathrm{mg} / \mathrm{kg})$ and xylazine $(10 \mathrm{mg} / \mathrm{kg})$. Additional injections of a $3: 1$ mixture of ketamine hydrochloride and xylazine were given to maintain the animal in an areflexic state. The body temperature of the animal was maintained with a heating pad and monitored. The anesthetized animal was fixed to a stereotaxic instrument and the skin on the head was incised to expose the skull surface. A head holder was then mounted between the bregma and lambda on the skull and fastened to the stereotaxic instrument to immobilize the head during the recording sessions. The temporal bone was removed to expose the auditory cortex, and the occipital bone was removed to expose the cerebellum. After a small slit had been carefully opened in dura matter, the mesh intracortical electrode was inserted into the cerebellum to record the spontaneous neural activities, and the guide cannula electrode was inserted into the auditory cortex to record the auditory evoked potentials (AEPs). The mesh intracortical electrode was coated with molten glucose of polyethylene glycol (PEG) (\#4000 MW2700-3500, Nakalai Tesque, Inc., Kyoto, Japan) to improve the mechanical stiffness of a flexible insertion site and thereby facilitate insertion (PEG dissolves in the brain, after implantation.). The ECoG electrode was epidurally placed on the auditory cortex to record the AEPs without removal of the dura matter.

The neural recordings were performed in an electrically shielded, darkened sound-attenuated room. For AEP recordings, auditory stimuli were delivered from a speaker (TS-T70, Pioneer Corporation, Kanagawa, Japan) placed $10 \mathrm{~cm}$ from the head. Stimuli were $50 \mathrm{~ms}$ broadband noise at 20-, 40-, and 80-dB SPL and $50 \mathrm{~ms}$ tone bursts of 1,4 , and $16 \mathrm{kHz}$ at $80-\mathrm{dB}$ SPL with a rise and fall time of $5 \mathrm{~ms}$ for recording by the ECoG electrode, or $100 \mathrm{~ms}$ tone bursts of $10 \mathrm{kHz}$ at $70-\mathrm{dB}$ SPL with a rise and fall time of $5 \mathrm{~ms}$ for recording by the guide cannula electrode. The recorded responses of the AEPs for the ECoG electrode were amplified with a band-pass filter $(0.3-3.0 \mathrm{kHz})$ (RA16, Tucker-Davis Technologies, Inc., Alachua, Florida, USA) and digitized at a sampling rate of $12,207 \mathrm{~Hz}$ with an RX5 system (Tucker-Davis Technologies, Inc.). The recorded responses of the AEPs for the guide cannula electrode were amplified with a band-pass filter $(0.1 \mathrm{~Hz}-3.0 \mathrm{kHz})$ (DAM80, World Precision Instruments, Inc., Sarasota FL, USA) and digitized at a sampling rate of $12,207 \mathrm{~Hz}$ with an RA8GA (Tucker-Davis Technologies, Inc.) and RX5 system. The spontaneous neural activities recorded by the mesh intracortical electrode were amplified with a bandpass filter (0.3-3.0 kHz) (RA16, Tucker-Davis Technologies, Inc.) and digitized at a sampling rate of $24,414 \mathrm{~Hz}$ with an RX5 system. These data were then stored on a computer hard disk for offline data analyses (Matlab, The Mathworks, Inc., Natick, MA, USA). The recorded AEP data were averaged across 100 trials. The DC bias of the average AEP for each channel was removed by subtracting the mean value for the $0.5 \mathrm{~s}$ prestimulus period from the data. The spikes from the mesh intracortical electrode were isolated by custom-made window discriminator software in which the amplitude threshold was set at four standard deviations, and inter-spike intervals were longer than $1 \mathrm{~ms}$. The signal-to-noise ratio (SNR) was defined as the peak-to-peak amplitude of each waveform divided by twice the standard deviation of the data from the isolated data (Nordhausen et al., 1996). Once the recording had been completed, the animal was killed with an intraperitoneal injection of a lethal dose of sodium pentobarbital.

\section{RESULTS}

\section{SHRINKAGE EFFECT OF CURING PROCESS}

We examined the effect of the shrinkage of PSPI thicknesses. As shown in Figure 3, the mean shrinkage of the thickness from softbaked to post-baked PSPI was $23.46 \% \pm 2.12$ (mean \pm SD) from 


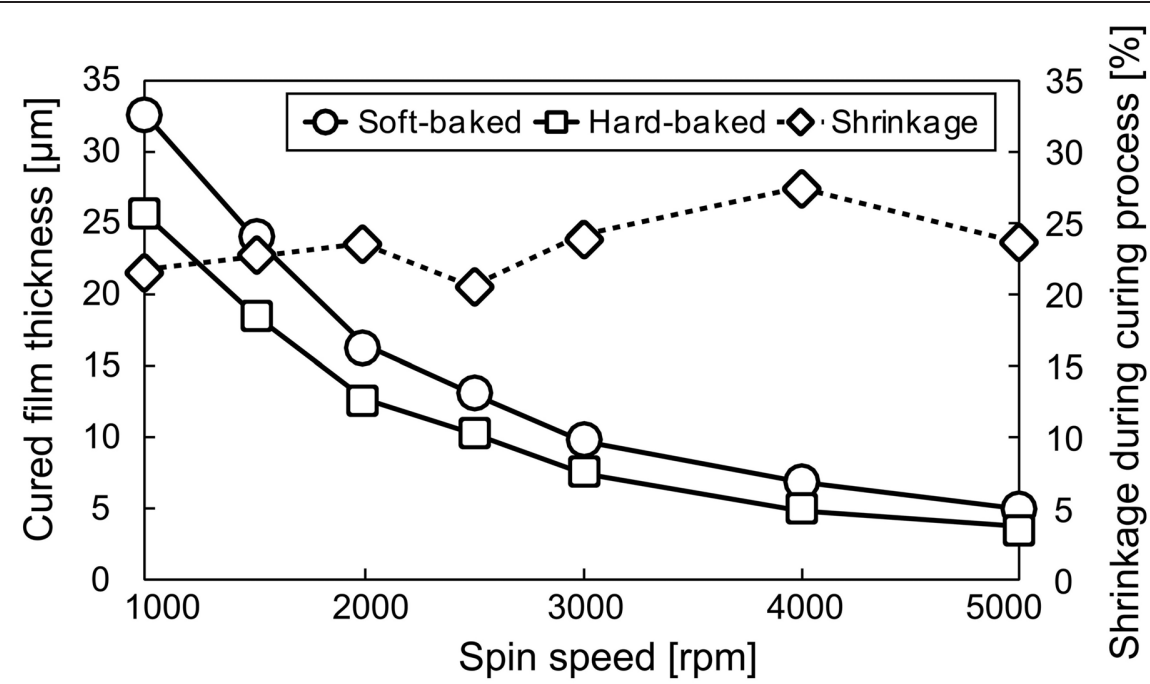

FIGURE 3 | Cured film thickness and spin-speed curves for Fujifilm Durimide 7510.

1000 to $5000 \mathrm{rpm}$. The large thickness showed slightly smaller shrinkage vertically than the small one. This result shows that the shrinkage effect was smaller for our chosen PSPI (Fujifilm Durimide 7510) than for the previously reported Probimide 7520 PSPI (Arch Chemicals, Columbus, OH, USA), which shrank vertically by about $40-50 \%$ during the curing process (Rousche et al., 2001). The fact that the PSPI used in this study shrinks in a similar manner horizontally and vertically during the curing process is evidence that it offers better performance in terms of design and processing than the previously reported PSPI.

Table 2 summarizes the shrinkage effect results. At 1000 and $2000 \mathrm{rpm}$, the top face seemed to pull inside, leading to about $20 \%$ shrinkage. Shrinkage in the bottom face was slightly smaller than in the top face, which may be due to the substrate support. At $4000 \mathrm{rpm}$, the gap or circular shapes expanded to become about $10-15 \%$ larger at the top and bottom faces. The stretch of the gap shape at the bottom face was smaller than at the top face, whereas the stretch of the circular shape was almost equivalent between the top and bottom shapes.

On the basis of the examination results and discussion (See Discussion), we chose the coating spin speed of $1600 \mathrm{rpm}$ for base layer thickness of about $15 \mu \mathrm{m}$ to ensure sufficient mechanical stiffness for placement on or insertion into brain tissue, and $5000 \mathrm{rpm}$ for top insulating layer thickness of about $3 \mu \mathrm{m}$ to minimize the bump between the metallization layer and top layer for smooth contact with brain tissue. In the mesh intracortical electrodes, the insulated probe width in the mesh area was $30 \mu \mathrm{m}$ and the minimum space between the probes was $20 \mu \mathrm{m}$. The area of the recording microelectrode in the metallization layer $(50 \mu \mathrm{m}$ in diameter) was more than $20 \%$ larger than the aperture area in the top layer ( $40 \mu \mathrm{m}$ in diameter) (See Designs Of Neural Electrodes in Methods). A $2500 \mathrm{rpm}$ coating speed was chosen for the PSPI of the guide cannula. The ideal thickness was about $10 \mu \mathrm{m}$, but we expected thickness smaller than $10 \mu \mathrm{m}$ because the coating was

Table 2 | Shrinkage effect of curing process.

\begin{tabular}{|c|c|c|c|c|c|c|c|}
\hline \multirow[b]{2}{*}{$\begin{array}{l}\text { Spin speed } \\
\text { [rpm] }\end{array}$} & \multirow[b]{2}{*}{ Description } & \multirow[b]{2}{*}{$\begin{array}{l}\text { Design } \\
\text { dimensions } \\
{[\mu \mathrm{m}]}\end{array}$} & \multicolumn{2}{|c|}{ Soft-baked } & \multicolumn{3}{|c|}{ Hard-baked } \\
\hline & & & $\begin{array}{l}\text { Fabrication } \\
\text { dimensions } \\
{[\mu \mathrm{m}]}\end{array}$ & $\begin{array}{l}\text { Shrinkage/expansion } \\
\text { effect compared to } \\
\text { design dimensions } \\
{[\%]}\end{array}$ & $\begin{array}{l}\text { Fabrication } \\
\text { dimensions } \\
{[\mu \mathrm{m}]}\end{array}$ & $\begin{array}{l}\text { Shrinkage/expansion } \\
\text { effect compared to } \\
\text { design dimensions [\%] }\end{array}$ & $\begin{array}{l}\text { Shrinkage/expansion } \\
\text { effect compared to } \\
\text { fabrication dimensions } \\
\text { in soft-baked [\%] }\end{array}$ \\
\hline \multirow[t]{2}{*}{1000} & Top face & 50 & 50.3 & 0.6 & 40.4 & -19.2 & -19.7 \\
\hline & Bottom face & & 64.5 & 29.0 & 53.4 & 6.8 & -17.2 \\
\hline \multirow[t]{2}{*}{2000} & Top face & 25 & 24.8 & -0.8 & 19.8 & -20.8 & -20.2 \\
\hline & Bottom face & & 30.7 & 22.8 & 25.9 & 3.6 & -15.6 \\
\hline \multirow[t]{2}{*}{4000 (gap) } & Top face & 20 & 20.6 & 3.0 & 23.9 & 19.5 & 16.0 \\
\hline & Bottom face & & 17.3 & -13.5 & 19.1 & -4.5 & 10.4 \\
\hline \multirow[t]{2}{*}{4000 (circle) } & Top face & 10 & 9.8 & -2.0 & 11.2 & 12.0 & 14.3 \\
\hline & Bottom face & & 7.3 & -27.0 & 6.3 & -37.0 & -13.7 \\
\hline
\end{tabular}


done with the upright position and some of the uncured PSPI may have flowed to the bottom.

\section{NEURAL ELECTRODE FABRICATION}

The three different architectures of PSPI-based multichannel flexible neural electrodes-ECoG, mesh intracortical, and guide cannula were successfully designed and fabricated. Photographs of the three fabricated neural electrodes are shown in Figure 4. Table 3 lists the sizes in the photomask designs and fabricated neural electrodes, which show the overall shrinkage and expansion effect of the fabrication. In the fabrication process, we did not observe delamination between the bottom PSPI layer and the chromium-coated glass substrate nor in the metal layer sandwiched by the PSPI. The thin and complicated mesh structure in the mesh intracortical electrode was lifted off from the wafer by coating a protective resist. No breakage in the mesh structure was observed. This indicates a stable fabrication process at lower cost with improvement of process yields. The processing time was about $12-15 \mathrm{~h}$ in our fabrication environment (excluding the time for designing and fabricating the photomasks).

As shown in Table 3, most of the dimensions of the fabricated neural electrodes were not significantly different from the designed ones. In the mesh intracortical electrode, large shrinkages were found in the interconnection line and the insulated probe width in the mesh area, and expansions were observed in the size of the reference electrode and the minimum space between insulated probes in the mesh area. These shrinkages and expansions may be due to the small area of the substrate support, but this effect could be minimized by improving the adhesion between the bottom face of the PSPI and the glass substrate. Since delamination and breakage were not observed under processing, this was not fatal for recording neural signals. The shrinkage effect of the ECoG electrode was not large compared to that in the curing test. The shrinkages were about a few percent or less than $8.5 \%$. The reason for this small shrinkage may be that the chromium layer on the glass substrate improves adhesiveness between the materials. Due to the curved surface of the guide cannula electrode, we were, unfortunately, only able to measure the shrinkage effect of the recording microelectrodes with the microscope.

As shown in Figure 6, the proposed shape of the guide cannula electrode for the microdialysis probe was achieved by using PSPI-based microfabrication technology. No delamination of the PSPI and no breakage were observed during the fabrication process. This implies that the coated PSPI tightly adhered to the curved surface of the guide cannula. The ideal coating thickness was about $10 \mu \mathrm{m}$, but it was about $2 \mu \mathrm{m}$ after the post-baking. This indicated that some of the spin-coated PSPI flowed to the bottom due to the upright position in the coating and curing processes, but the upright position allowed uniform coating on the cylindrical surface. The coating thickness of $2 \mu \mathrm{m}$ also showed stable physical properties of electric and mechanical insulation. The results for the guide cannula electrode showed that our

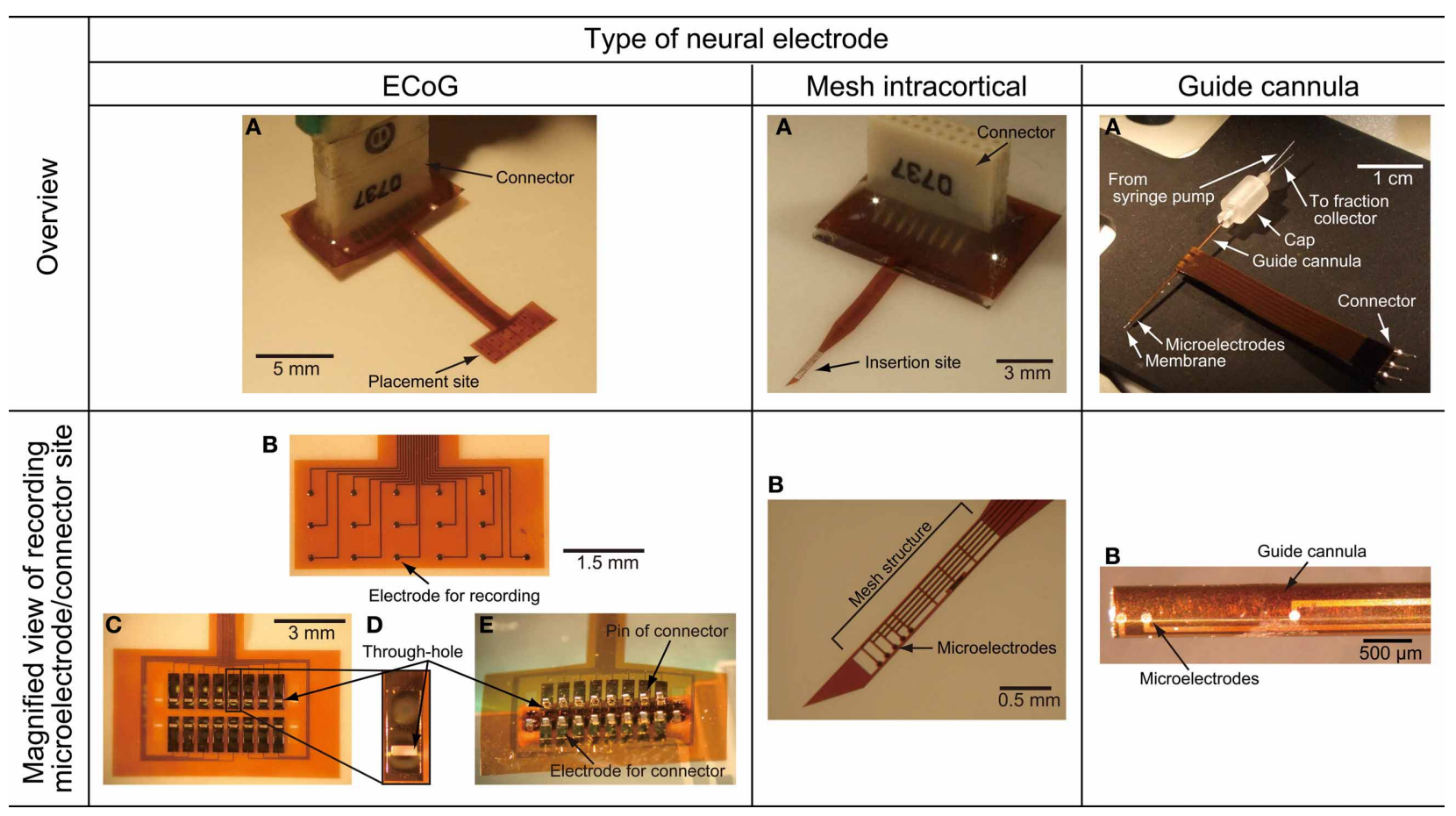

FIGURE 4 | Photographs of the fabricated ECoG electrode, mesh intracortical electrode, and guide cannula electrode of the microdialysis electrode. (A) Overview of the fabricated neural electrode. (B) Magnified view of recording microelectrodes or connector sites.
(C) Back face of the connector side of the ECoG electrode. (D) Magnified view of a through-hole for connector pins in the ECoG electrode. (E) Back face of connector side fitted with soldering pins of connector in the ECoG electrode. 


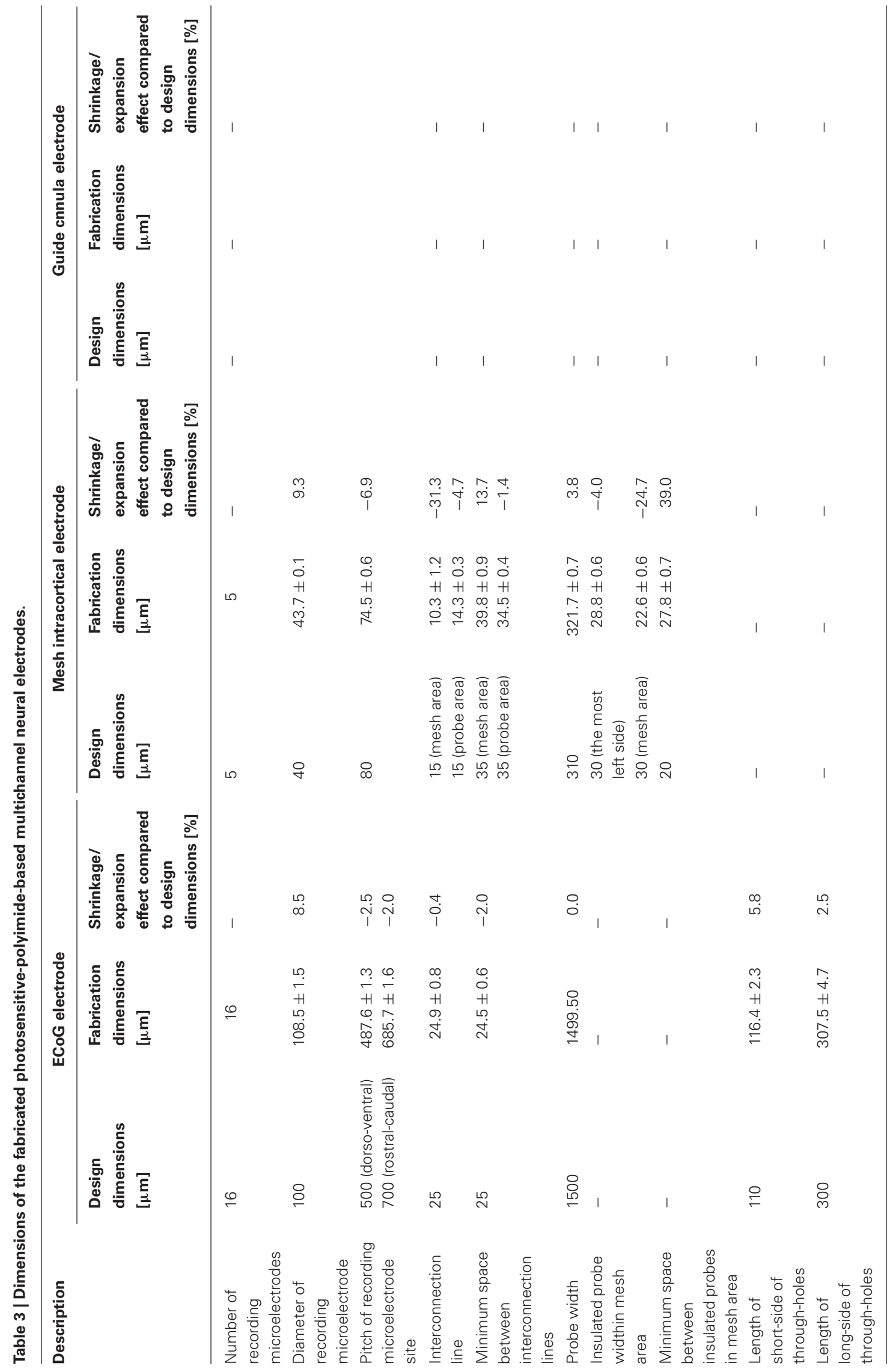


PSPI-based photolithographic patterning is not limited to a flat surface.

\section{ELECTRICAL CHARACTERISTICS}

The measured recording microelectrodes' impedances are shown in Figure 5. At $1 \mathrm{kHz}$, the average impedance ranged from $196.8 \pm 27.8 \mathrm{k} \Omega$ for the $100 \mu \mathrm{m}$ diameter ECoG electrode, $211.6 \pm 17.6 \mathrm{k} \Omega$ for the $100 \mu \mathrm{m}$ diameter guide cannula electrode, and $777.5 \pm 205.7 \mathrm{k} \Omega$ for the $40 \mu \mathrm{m}$ diameter mesh intracortical electrode. Figure 5A shows that the recording microelectrode's impedance tended to decrease with increasing frequency, probably reflecting the frequency effect on the capacitance in the metal-electrolyte interface, if we assume a typical equivalent circuit (Rubehn et al., 2009).

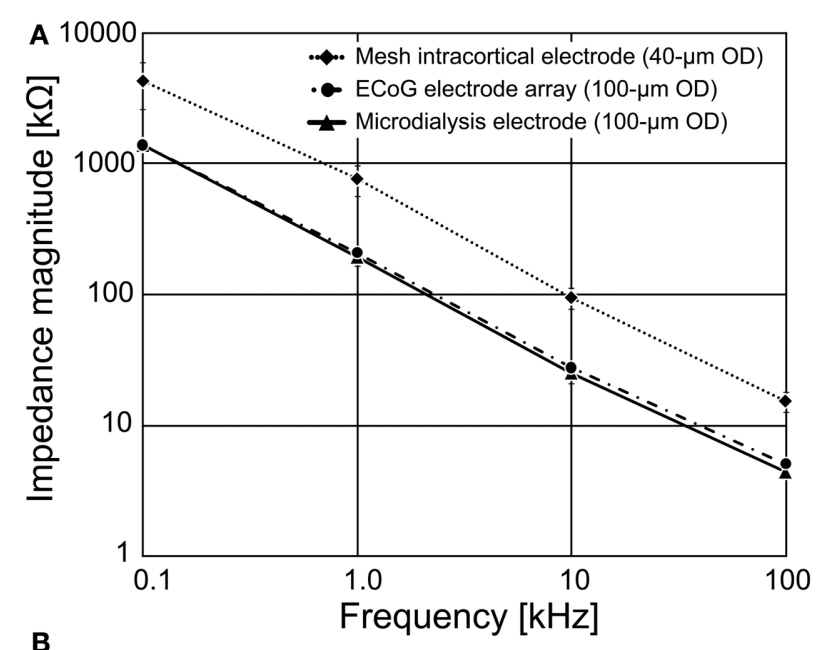

B

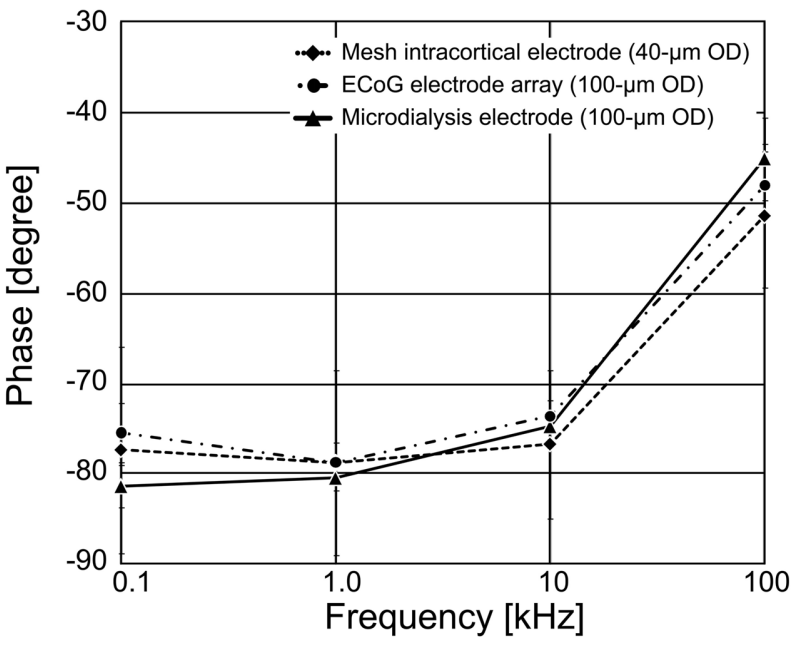

FIGURE 5 | Impedance spectroscopy results for the fabricated PSPI-based neural electrodes. The recording microelectrode's

impedances were measured in a $0.9 \%$ saline solution at room temperature. (A) The average magnitude of recording microelectrode's impedance for the $100 \mu \mathrm{m}$ diameter of the ECoG electrode and the guide cannula electrode, and the $40 \mu \mathrm{m}$ diameter of the mesh intracortical electrode, respectively.

(B) The average phase of recording microelectrode's impedance.

\section{In vivo RECORDING OF NEURAL ACTIVITIES}

In acute animal experiments, the three types of the flexible neural electrodes were successfully placed on or inserted into rat cortex. The ECoG electrode was placed on and fitted to the dura on the cortex. Neither breakage of an electrode nor injurious stress to the cortex was observed during the recording sessions, indicating that the ECoG electrode has sufficient flexibility. The mesh intracortical electrode was coated with the PEG and followed a straight trajectory to the cortex. None of the features bent, buckled, or delaminated. This shows that the mesh intracortical electrode with a PEG coating has sufficient mechanical stiffness for insertion into brain tissue and good flexibility after the PEG dissolves. The guide cannula electrode was also successfully inserted in the cortex without any breakage.

The electrophysiological performance of the neural electrodes was evaluated by conducting acute recordings in the auditory cortex or cerebellum of anesthetized rats. We succeeded in recording AEPs from the surface of the auditory cortex by all 16-channel recording microelectrodes of the ECoG electrode. Two examples of the recorded AEPs are shown in Figure 6. Figures 6A-C show the responses to the level-dependent activities of the broadband stimuli. The responses were confirmed in the broad recorded area because the stimuli contained a wide range of frequencies. Figures 6D-F show that the activities shift with sound frequency, as expected from the tonotopic organization of the auditory cortex (Sally and Kell, 1988; Kilgard and Merzenich, 1999; Ohl et al., 2000; Polley et al., 2007). These frequency-dependent areas appeared in an orderly sequence along $4 \mathrm{~mm}$ in the rostro-caudal direction (Sally and Kell, 1988; Kilgard and Merzenich, 1999; Ohl et al., 2000; Polley et al., 2007). In the anterior auditory cortex, large responses were observed to high frequencies in the rostral area and in the area between the anterior and primary auditory cortex, and to low frequencies in the caudal area of the primary auditory cortex. This indicates that the ECoG electrode was placed over the area of the anterior and primary auditory cortex, with the recording area of $2.9 \times 1.2 \mathrm{~mm}$ in the 16 -channel ECoG electrode capable of measuring AEPs on the auditory cortices. We expect that recording microelectrodes with smaller site diameters and optimized site arrangements would reveal the tonotopy in the auditory cortex more precisely. The ECoG electrodes are considered to have sufficient strength and durability because the recorded AEPs remained stable for more than $24 \mathrm{~h}$ even if the ECoG electrode was reused several times. We assumed that the flexible ECoG electrode followed small movements due to breathing or other spontaneous movements and that the recording points were always applied with sufficient pressure for fitting to the dura of the cortex. The transparent property of PSPI permitted easy replacement of the ECoG electrode, meaning that we can adjust the locations of the recording microelectrodes to keep them away from cerebral vessels.

We also succeeded in recording neural signals with the mesh intracortical electrode. Figure 7 shows the recorded spontaneous activities. The inset shows spike waveforms that were detected with our spike-sorting software (see In vivo Neural Recordins in Methods) and had an SNR higher than 4. The spikes had durations of about $1 \mathrm{~ms}$ and amplitudes of $96 \pm 9.0$ (SD) $\mu \mathrm{V}$, corresponding to SNRs of $4.7 \pm 0.44$ (SD). The SNR values fell to 


\section{A $20-d B$ SPL}

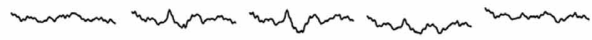

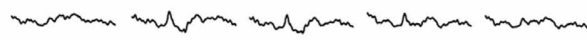

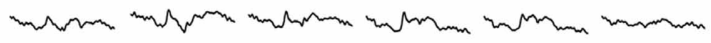

\section{B $40-\mathrm{dB}$ SPL}

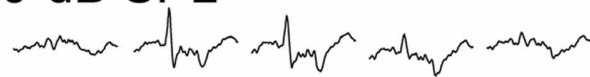

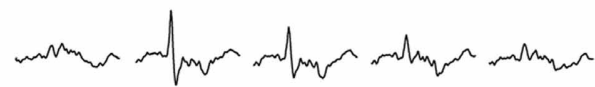

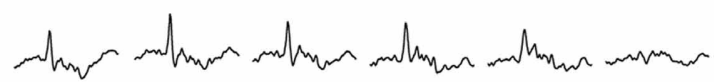

$$
\text { 80-dB SPL }
$$

FIGURE 6 | Auditory evoked potentials recorded from the auditory cortex of an anesthetized rat by the ECoG electrode. The data shown here are averages across 100 stimulus presentations. (A-C) Auditory stimuli were $50 \mathrm{~ms}$ broadband noise at 20-, 40-, and 80-dB SPL,

\section{D $1 \mathrm{kHz}$}

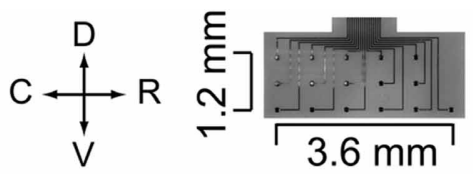

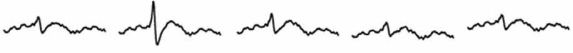

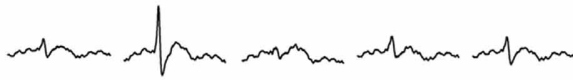

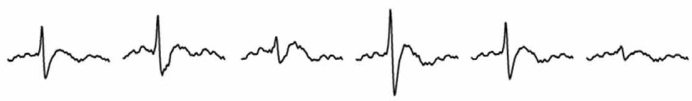

\section{E $4 \mathrm{kHz}$}
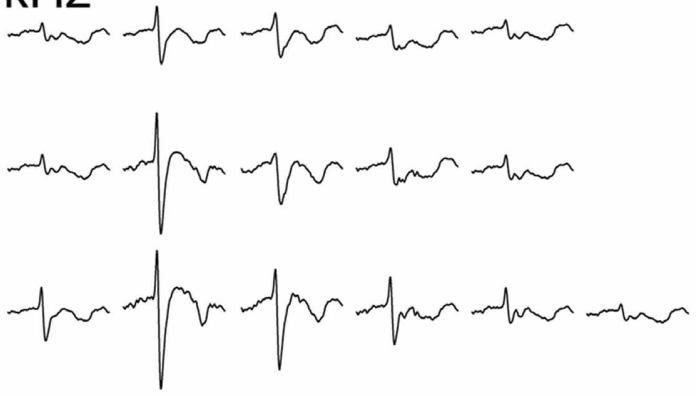

\section{F $16 \mathrm{kHz}$}

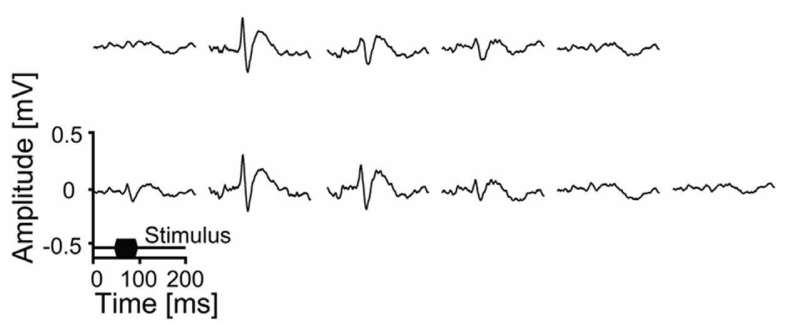

and (D-F) $50 \mathrm{~ms}$ pure tones of 1, 4, and $16 \mathrm{kHz}$ at $80-\mathrm{dB}$ SPL (D-F). Each set of data represent the same alignment as that in the right-top picture, which shows the alignment of 16-channel recording microelectrodes. a lower range than those reported previously (4-7; Nordhausen et al., 1996; Vetter et al., 2004), probably because the recording microelectrode impedance was lower than that in the previous reports. In the recording experiment with the guide cannula electrode, the AEPs were also successfully recorded from the auditory cortex. Figure 8 shows an averaged AEP in response to the tone burst stimuli.

\section{DISCUSSION}

For comparison, our fabrication method and 12 others for flexible material-based neural electrodes are listed in Table 4. All of these fabrication methods produce flexible material-based neural electrodes. In comparison to the other methods which involve time-consuming processes or use material with size limitations, our method requires only one type of PSPI as an insulation material and the design and fabrication versatility can be expanded to various neural electrode architectures with fine patterning of non-flat substrate. Excluding the time for designing and fabricating the photomasks, the processing time in our fabrication environment is about $12-15 \mathrm{~h}$, which satisfies the demand for fast and cost-effective fabrication for daily electrophysiological experiments depending on an experimental purpose. With a mask writer, such as D-light DL-1000 (NanoSystem Solutions, Inc., Tokyo, Japan), the processing time for fabricating a photomask 


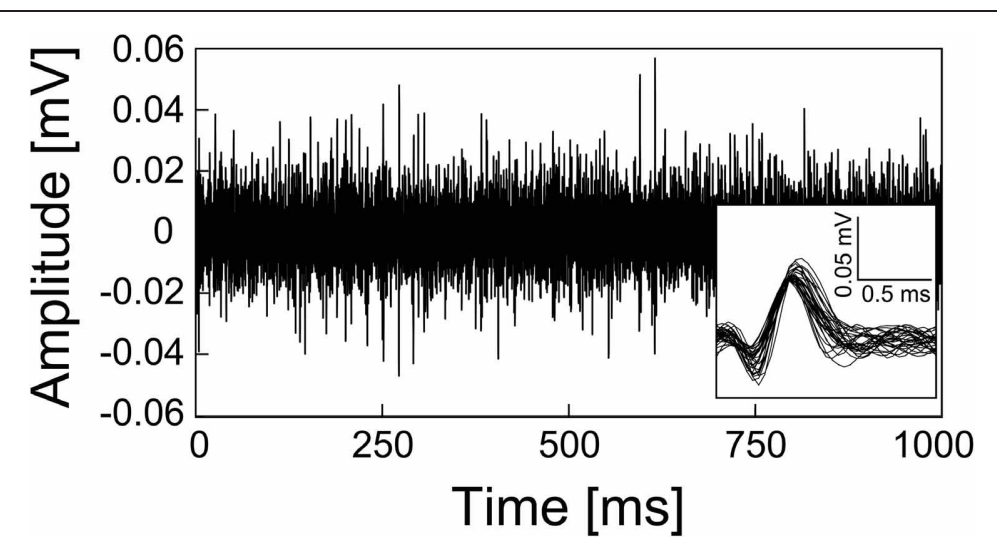

FIGURE 7 | Spontaneous activities recorded from rat cerebellar cortex by the mesh intracortical electrode. Lower right shows a magnified view of the spike waveforms from the recorded spontaneous activities.

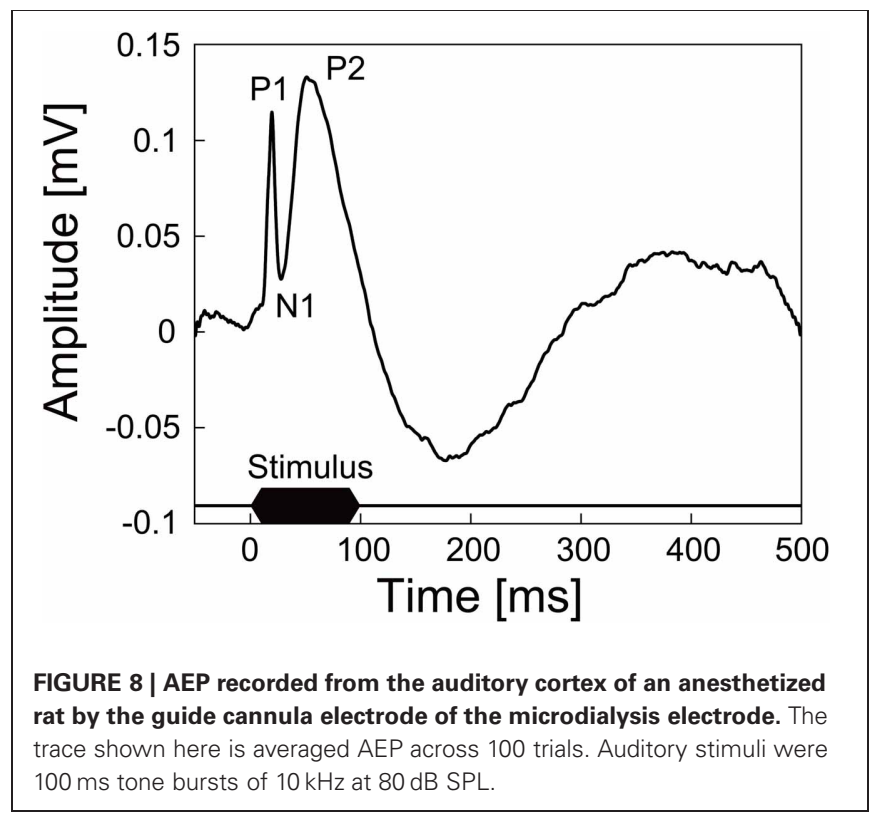

with submicron patterning accuracy is less than a few hours, so that the time for mask fabrication does not have large effects on the total processing time.

From the results on the shrinkage effect of curing process, we expected the deformation in the curing process between the photomask design and the post-baked design to be $15-20 \%$ of the matching error and the line shape to not be perpendicular but relatively bowl-like after the curing process. Thus, according to the material specifications and our results, the process limitation is as small as $\mathrm{L} / \mathrm{S}=5 / 5 \mu \mathrm{m}$ and the margin in the photomask design should be an upper layer more than $20 \%$ wider than the bottom layer. Further, considering the success of fabrication on the non-flat surface, we can conclude that our method based on PSPI allows not only any precise design and fabrication of the various architectures of flexible multichannel neural electrodes listed in Table 4, but also broadens the design flexibility and expands the fabrication capability.
The observed average impedance for the $40 \mu \mathrm{m}$ diameter is slightly small for recording single- or multiunit neural activities, since the average impedance of similar flexible neural electrodes ranges from about $1-2 \mathrm{M} \Omega$ at $1 \mathrm{kHz}$ (Rousche et al., 2001; Takeuchi et al., 2004), but the microelectrodes could still record single-unit activities. The recording microelectrodes may require narrowing of the exposed size from 40 to 30 or $20 \mu \mathrm{m}$. The impedance for $100 \mu \mathrm{m}$ diameter is adequate for recording local field potentials (Takahashi et al., 2003; Hollenberg et al., 2006).

The integration of other functions with a neural electrode, such as the multichannel guide cannula electrode of the microdialysis probe in this study would advance our understanding of the mechanisms of neural interactions, including complex electrical and biochemical reactions. In previously proposed methods for combining a recording microelectrode with a microdialysis probe, a tungsten needle was glued to a guide cannula of a microdialysis (Gruss et al., 1999), a silver wire was inserted into a guide cannula (Obrenovitch et al., 1994), and a microdrive of bundled electrodes was glued to a guide cannula of a microdialysis probe (Ludvig et al., 1994). These methods of simply attaching a metal needle to a guide cannula are largely invasive due to the increment of probe's volume and make it difficult to precisely position the tip of recording microelectrodes to the target. In contrast, our method places the recording microelectrodes without increasing the volume and with precise control of their position. This lower invasiveness is another advantage of our method. In this study, we placed three recording microelectrodes on one side the guide cannula and also three on the other side after a $180^{\circ}$ rotation (not shown in the figure). It would be technically possible to place additional microelectrodes by adopting finer rotation steps.

Regarding the insertion volume of neural electrodes, we found that a few hours might be needed to obtain stable recordings. With both the mesh intracortical electrode and the guide cannula electrode, it took more than $3 \mathrm{~h}$ after electrode insertion to the cortex until we could make stable recordings. This was probably because there was initially a large physical distance between the recording microelectrode sites and the target neurons due to the PEG coating on the insertion sites for the mesh intracortical 


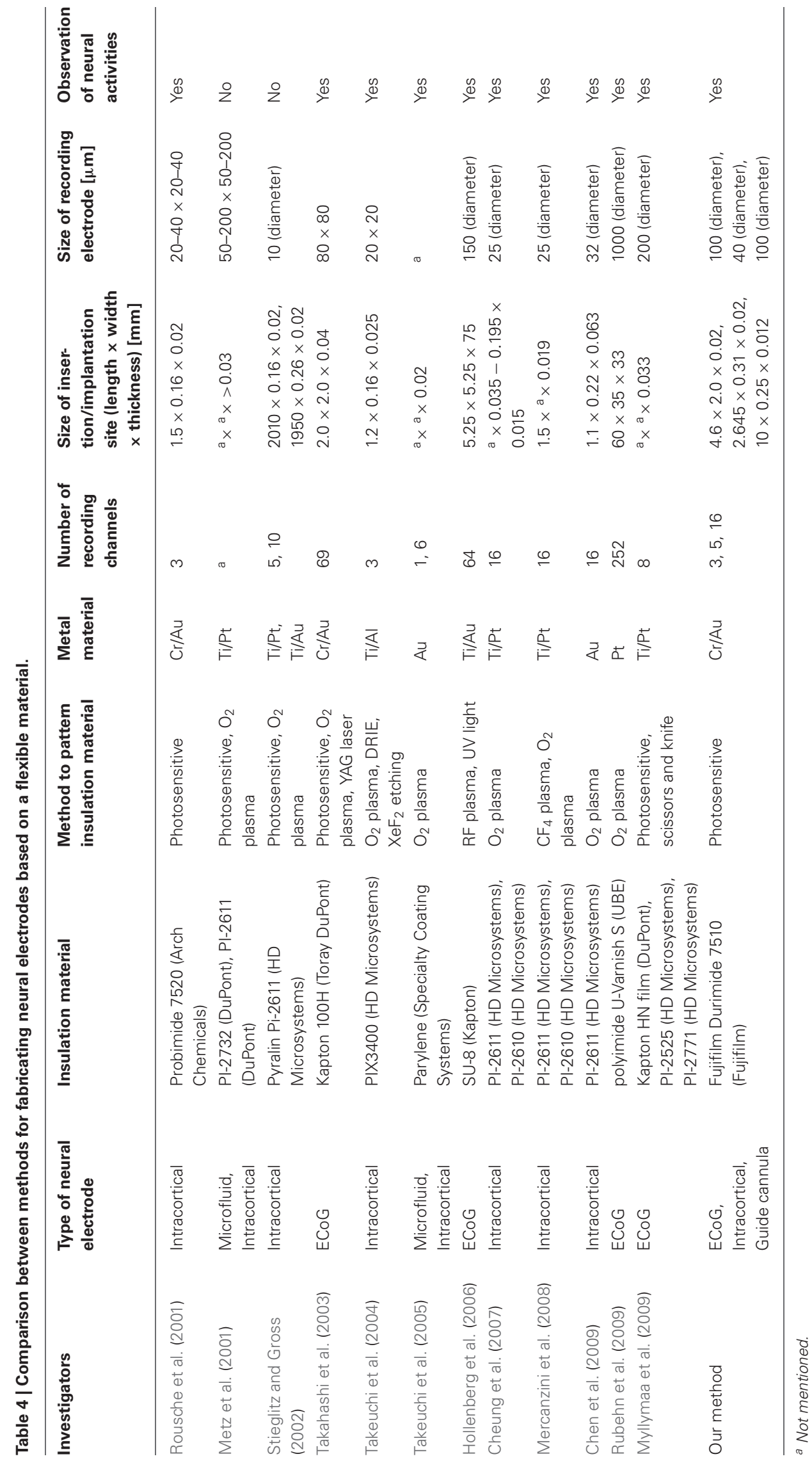


electrode, and because the relatively large diameter of $0.5 \mathrm{~mm}$ caused local tissue injuries at electrode insertion for the guide cannula electrode. Although the coating on the insertion site of the mesh intracortical electrode should dissolve soon after implantation in the brain, it takes some time for the PEG to diffuse and be absorbed sufficiently to reduce the distance (Palmer, 1978). For the guide cannula electrode, we consider this amount of waiting time practically acceptable, because a few hour waiting time is required anyways as a part of the washout period in microdialysis experiments to obtain a table baseline. The waiting time may be shortened to 1-2 h (Obrenovitch et al., 1994) if perfusion in the microdialysis probe can be used to wash out an unwanted substance.

In conclusion, we have shown that PSPI-based photolithographic patterning permits not only a precise and complex geometry design but also fabrication on a non-flat substrate by considering the shrinkage effect of PSPI. The fabrication of various types of electrodes and their use in recording neuronal activities in acute animal experiments were successful. Although further research such as a chronic electrophysiological study is needed to show the long-term stability, this success makes us believe that this PSPI-based fabrication is a powerful method, permitting a flexible design, and the easy optimization of electrode architectures for a variety of electrophysiological experimental researches with improved neural recording performance.

\section{ACKNOWLEDGMENTS}

We thank T. Hoshino for helpful comments on the manuscript. Clean room processing was carried out at Photo Precision Co., Ltd with the support of T. Narisawa. This research was partially supported by a Grant-in-Aid for Young Scientists (B) 23700495 from the Ministry of Education, Culture, Sports, Science, and Technology of Japan.

\section{REFERENCES}

Campbell, P. K., Jones, K. E., Huber, R. J., Horch, K. W., and Normann, R. A. (1991). A silicon-based, three-dimensional neural interface: manufacturing processes for an intracortical electrode array. IEEE Trans. Biomed. Eng. 38, 758-768.

Charlson, E. M., Charlson, E. J., and Sabeti, R. (1992). Temperature selective deposition of Parylene-C. IEEE Trans. Biomed. Eng. 39, 202-206.

Chen, Y. Y., Lai, H. Y., Lin, S. H., Cho, C. W., Chao, W. H., Liao, C. H., Tsang, S., Chen, Y. F., and Lin, S. Y. (2009). Design and fabrication of a polyimide-based microelectrode array: application in neural recording and repeatable electrolytic lesion in rat brain. J. Neurosci. Methods $182,6-16$.

Cheung, K. C., Renaud, P., Tanila, H., and Djupsund, K. (2007). Flexible polyimide microelectrode array for in vivo recordings and current source density analysis. Biosens. Bioelectron. 22, 1783-1790.

González, C., and Rodríguez, M. (1997). A flexible perforated microelectrode array probe for action potential recording in nerve and muscle tissues. J. Neurosci. Methods 72, 189-195.

Gruss, M., Bredenkötter, M., and Braun, K. (1999). N-methylD-aspartate receptor-mediated modulation of monoaminergic metabolites and amino acids in the chick forebrain: an in vivo microdialysis and electrophysiology study. J. Neurobiol. 40, 116-135.

Hanna, G. R., and Johnson, R. N. (1968). A rapid and simple method for the fabrication of arrays of recording electrodes. Electroencephalogr. Clin. Neurophysiol. 25, 284-286.

Hollenberg, B. A., Richards, C. D., Richards, R., Bahr, D. F., and Rector, D. M. (2006). A MEMS fabricated flexible electrode array for recording surface field potentials. J. Neurosci. Methods 153, 147-153.

Jackson, N., Sridharan, A., Anand, S., Baker, M., Okandan, M., and Muthuswamy, J. (2010). Long-term neural recordings using MEMS based movable microelectrodes in the brain. Front. Neuroeng. 3:10. doi: 10.3389/fneng.2010.00010

Kilgard, M. P., and Merzenich, M. M. (1999). Distributed representation of spectral and temporal information in rat primary auditory cortex. Hear. Res. 134, 16-28.

Loeb, G. E., Bak, M. J., Salcman, M., and Schmidt, E. M. (1977). Parylene as a chronically stable, reproducible microelectrode insulator. IEEE Trans. Biomed. Eng. 24, 121-128.

Ludvig, N., Potter, P. E., and Fox, S. E. (1994). Simultaneous single-cell recording and microdialysis within the same brain site in freely behaving rats: a novel neurobiological method. J. Neurosci. Methods 55, 31-40.

Mercanzini, A., Cheung, K., Buhl, D. L., Boers, M., Maillard, A., Colin, P., Bensadoun, J. C., Bertsch, A., and Renaud, P. (2008). Demonstration of cortical recording using novel flexible polymer neural probes. Sens. Actuators A Phys. 143, 90-96.

Metz, S., Holzer, R., and Renaud, P. (2001). Polyimide-based microfluidic devices. Lab Chip 1, 29-34.
Muthuswamy, J., Anand, S., and Sridharan, A. (2011). Adaptive movable neural interfaces for monitoring single neurons in the brain. Front. Neurosci. 5:94. doi: 10.3389/fnins.2011.00094

Myllymaa, S., Myllymaa, K., Korhonen, H., Töyräs, J., Jääskeläinen, J. E., Djupsund, K., Tanila, H., and Lappalainen, R. (2009). Fabrication and testing of polyimide-based microelectrode arrays for cortical mapping of evoked potentials. Biosens. Bioelectron. 4, 3067-3072.

Najafi, K., Ji, J., and Wise, K. D. (1990). Scaling limitations of silicon multichannel recording probes, IEEE Trans. Biomed. Eng. 37, 1-11.

Nordhausen, C. T., Maynard, E. M., and Normann, R. A. (1996). Single unit recording capabilities of a 100 microelectrode array. Brain Res. 726, 129-140.

Obrenovitch, T. P., Urenjak, J., and Zilkha, E. (1994). Intracerebral microdialysis combined with recording of extracellular field potential: a novel method for investigation of depolarizing drugs in vivo. Br. J. Pharmacol. 113, 1295-1302.

Ohl, F. W., Scheich, H., and Freeman, W. J. (2000). Topographic analysis of epidural pure-tone-evoked potentials in gerbil auditory cortex. J. Neurophysiol. 83, 3123-3132.

Palmer, C. (1978). A microwire technique for recording single neurons in unrestrained animals. Brain Res. Bull. 3, 285-289.

Paxinos, G., and Watson, C. (2007). The Rat Brain in Stereotaxic Coordinates, 6th Edn. Amsterdam: Elsevier.

Polley, D. B., Read, H. L., Storace, D. A., and Merzenich, M. M. (2007).
Multiparametric auditory receptive field organization across five cortical fields in the albino rat. $J$. Neurophysiol. 97, 3621-3638.

Rothschild, R. M. (2010). Neuroengineering tools/applications for bidirectional interfaces, brain-computer interfaces, and neuroprosthetic implants-a review of recent progress. Front. Neuroeng. 3:112. doi: 10.3389/fneng.2010. 00112

Rousche, P. J., Pellinen, D. S., Pivin, D. P., Williams, J. C., Vetter, R. J., and Kipke, D. R. (2001). Flexible polyimide-based intracortical electrode arrays with bioactive capability. IEEE Trans. Biomed. Eng. 48, 361-371.

Rubehn, B., Bosman, C., Oostenveld, R., Fries, P., and Stieglitz, T. (2009). A MEMS-based flexible multichannel ECoG-electrode array. J. Neural Eng. 6, 036003.

Sally, S. L., and Kell, J. B. (1988). Organization of auditory cortex in the albino rat: sound frequency. $J$. Neurophysiol. 59, 1627-1638.

Stieglitz, T., Beutel, H., Schuettler, M., and Mayer, J. (2000). Micromachined, polyimide-based devices for flexible neural interfaces. Biomed. Microdevices 2, 283-294.

Stieglitz, T., and Gross, M. (2002). Flexible BIOMEMS with electrode arrangements on front and back side as key component in neural prostheses and biohybrid systems. Sens. Actuators B Chem. 83, 8-14.

Sun, Y., Lacour, S. P., Brooks, R. A., Rushton, N., Fawcett, J., and Cameron, R. E. (2009). Assessment of the biocompatibility of photosensitive polyimide for implantable 
medical device use. J. Biomed. Mater. Res. A 90, 648-655.

Takahashi, H., Ejiri, T., Nakao, M., Nakamura, N., Kaga, K., and Hervé, T. (2003). Microelectrode array on folding polyimide ribbon for epidural mapping of functional evoked potentials. IEEE Trans. Biomed. Eng. 50, 510-516.

Takahashi, H., Suzurikawa, J., Nakao, M., Mase, F., and Kaga, K. (2005). Easy-to-prepare assembly array of Tungsten microelectrodes. IEEE Trans. Biomed. Eng. 52, 952-956.

Takeuchi, S., Suzuki, T., Mabuchi, K., and Fujita, H. (2004). 3D flexible multichannel neural probe array. J. Micromech. Microeng. 14, 104-108.

Takeuchi, S., Ziegler, D., Yoshida, Y., Mabuchi, K., and Suzuki, T. (2005). Parylene flexible neural probe with micro fluidic channel. Lab Chip 5, 519-523.

Vetter, R. J., Williams, J. C., Hetke, J. F., Nunamaker, E. A., and Kipke, D. R. (2004). Chronic neural recording using silicon-substrate microelectrode arrays implanted in cerebral cortex. IEEE Trans. Biomed. Eng. 51, 896-904.

Wise, K. D., and Najafi, K. (1991). Microfabrication techniques for integrated sensors and Microsystems. Science 254, 1335-1342.

Conflict of Interest Statement: The authors declare that the research was conducted in the absence of any commercial or financial relationships that could be construed as a potential conflict of interest.

Received: 22 November 2011; paper pending published: 27 April 2012; accepted: 31 May 2012; published online: 18 June 2012
Citation: Kato YX, Furukawa S, Samejima K, Hironaka $N$ and Kashino $M$ (2012) Photosensitive-polyimide based method for fabricating various neural electrode architectures. Front. Neuroeng. 5:11. doi: 10.3389/fneng. 2012.00011

Copyright (C) 2012 Kato, Furukawa, Samejima, Hironaka and Kashino. This is an open-access article distributed under the terms of the Creative Commons Attribution Non Commercial License, which permits non-commercial use, distribution, and reproduction in other forums, provided the original authors and source are credited. 